\title{
Assessing the Variability of Heavy Rainfall during October to December Rainfall Season in Tanzania
}

\section{Lovina Peter Japheth ${ }^{1}$, Guirong Tan², Ladislaus Benedict Chang'a ${ }^{1 *}$, Agnes Lawrence Kijazi1, Kantamla Biseke Mafuru', Isack Yonah' ${ }^{1}$}

${ }^{1}$ Tanzania Meteorological Authority, Dar es Salaam, Tanzania

${ }^{2}$ Nanjing University of Science and Technology, Nanjing, China

Email: *changa60@hotmail.com

How to cite this paper: Japheth, L.P., Tan, G., Chang'a, L.B., Kijazi, A.L., Mafuru, K.B. and Yonah, I. (2021) Assessing the Variability of Heavy Rainfall during October to December Rainfall Season in Tanzania. Atmospheric and Climate Sciences, 11, 267-283. https://doi.org/10.4236/acs.2021.112016

Received: January 17, 2021

Accepted: March 7, 2021

Published: March 10, 2021

Copyright $\odot 2021$ by author(s) and Scientific Research Publishing Inc. This work is licensed under the Creative Commons Attribution International License (CC BY 4.0).

http://creativecommons.org/licenses/by/4.0/

(c) (i) Open Access

\begin{abstract}
Heavy rainfall is one of the primary causes of flood during rainy season in Tanzania leading to severe socio-economic impacts. The study aimed at assessing and characterizing the variability of Heavy Rainfall Events (HREs) using Empirical Orthogonal Function (EOF), Mann-Kendal (MK) trend test, Correlation and Composite analysis methods. Based on the daily-observed precipitation and reanalysis data sets for the October to December (OND) rainfall season of 35 years (1981-2015), the spatial and temporal characteristics of HREs in Tanzania are studied. The relationship between heavy rainfall (HR) and large-scale circulation anomalies including the Indian Ocean dipole (IOD) and El Niño southern oscillation (ENSO) indices was assessed. The study found that, approximately 590 HREs were concentrated over northern sector and coastal belt of Tanzania. The monthly variability indicates that HREs are more pronounced in December followed by November while October being the least affected. The occurrence of HREs over the Lake Victoria, Kigoma and Tabora is largely attributed to low-level convergence of westerlies and enhanced moisture from Congo basin accompanied by a pronounced rising limb of Indian Walker circulation cell. A time-series analysis of HRE exhibits an inter-annual variation characterized by a slightly increasing trend, though the computed trends were not statistically significant at $95 \%$ confidence level. In most part of Tanzania HREs were positively correlated with both ENSO and IOD indices, underscoring the critical role of ENSO and Indian Ocean dynamic in modulating rainfall variability over the region. In general, it has been found that most of the HREs are generally triggered or amplified by large-scale circulation patterns such as ENSO and IOD.
\end{abstract}


Keywords

Rainfall Variability, Heavy Rainfall Events, OND, Tanzania

\section{Introduction}

Recent reports from the Intergovernmental Panel on Climate Change [1] [2] have indicated the observed increase in the frequency and intensity of extreme events across much of the world. The frequency and intensity of heavy precipitation events is increasing in some parts of Africa [1]. Understanding the patterns and variability of Heavy Rainfall Events (HREs) is critical and pre-requisite inputs for informed decision making and designing an effective early warning system of these extremes and for reducing loss of life and properties resulting from HREs. These extremes are associated with devastating impacts to the livelihoods of the communities in both rural and urban areas, including impact on rain-fed agriculture and pastoralism [3], public health [4] and water and food security [5] [3]. Several studies have attempted to map and characterize specific extreme event with the purpose of determining the mechanisms involved in its evolution and dynamic, for instance, the El Niño related extreme rainfall events that occurred in southern Africa [6], the drought in 2005 [7] and floods in 1994 [8] and 1997 [9] over East Africa (EA).

The rainfall patterns over the East Africa( EA) region are complex, are characterized by stronger spatial-temporal variability and are influenced by multiple factors including El Niño Southern Oscillation (ENSO) and the ocean dynamics over the Indian Ocean [10] [11]. ENSO is one of the main climate signals that influence the climate and weather globally [8]. According to [12] the short rains in EA are linked to ENSO due to zonal pressure gradients created by sea surface temperature anomalies (SSTA) over Indian Ocean. Studies by [13] [14] and [15] provide detailed information and mechanism on how ENSO influences the climate of Tanzania, whereby the above (below) normal rainfall occurs during El Niño (La Niña) episodes.

Over the recent decade, Tanzania has been experiencing increased frequencies and intensities of HREs in different parts of the country that lead to increased loss of life and properties. HREs are one of the primary causes of floods in Tanzania and found to be a repetitive scenario during OND rainfall season leading to loss of people's lives and properties. For instance, on $13^{\text {th }}$ and $14^{\text {th }}$ October, 2020 heavy rain of $103.4 \mathrm{~mm}$ and $58.6 \mathrm{~mm}$ respectively was recorded at Dar es salaam International Airport which caused devastating flood that leads to the death of 12 people and severe infrastructural damages. Unfortunately mapping the distribution and trend of HRE is still not well documented.

Therefore, this study aims at assessing the distribution and quantifying the variability of heavy rainfall during the OND rainfall season in Tanzania. Specifically, the analysis of temporal and spatial variability, trend and the main forcing 
factors linked with HREs over the region are the prerequisites of this study.

\section{Description of the Study Area}

The United Republic of Tanzania (URT) is located between $1^{\circ} \mathrm{S}$ and $12^{\circ} \mathrm{S}$ latitudes and $30^{\circ} \mathrm{E}$ and $40^{\circ} \mathrm{E}$ longitudes, and it is the largest country over East Africa. URT is constituted of Tanzania mainland and Tanzania Zanzibar (Unguja and Pemba Isles). Tanzania is bordered by Uganda and Kenya in the north while in the west it shares borders with Democratic Republic of Congo, Burundi and Rwanda. Complex and diverse topographical features that include, the presence of the Indian Ocean, Lake Victoria, Lake Tanganyika, and Lake Nyasa characterize the climate of Tanzania. The country has the snow capped and highest mountain in Africa, Mount Kilimanjaro with 5895 meters above sea level.

\section{Data and Methodology}

\subsection{Data}

The study used observed daily rainfall data sets for October, November and December spanning from 1981 to 2015, obtained from Tanzania Meteorological Authority (TMA). The observed data used was from 18 selected synoptic stations (Figure 1(b)). The heavy rainfall event (HRE) used in this study is defined as any event in which the amount of rainfall observed per day is equal to or
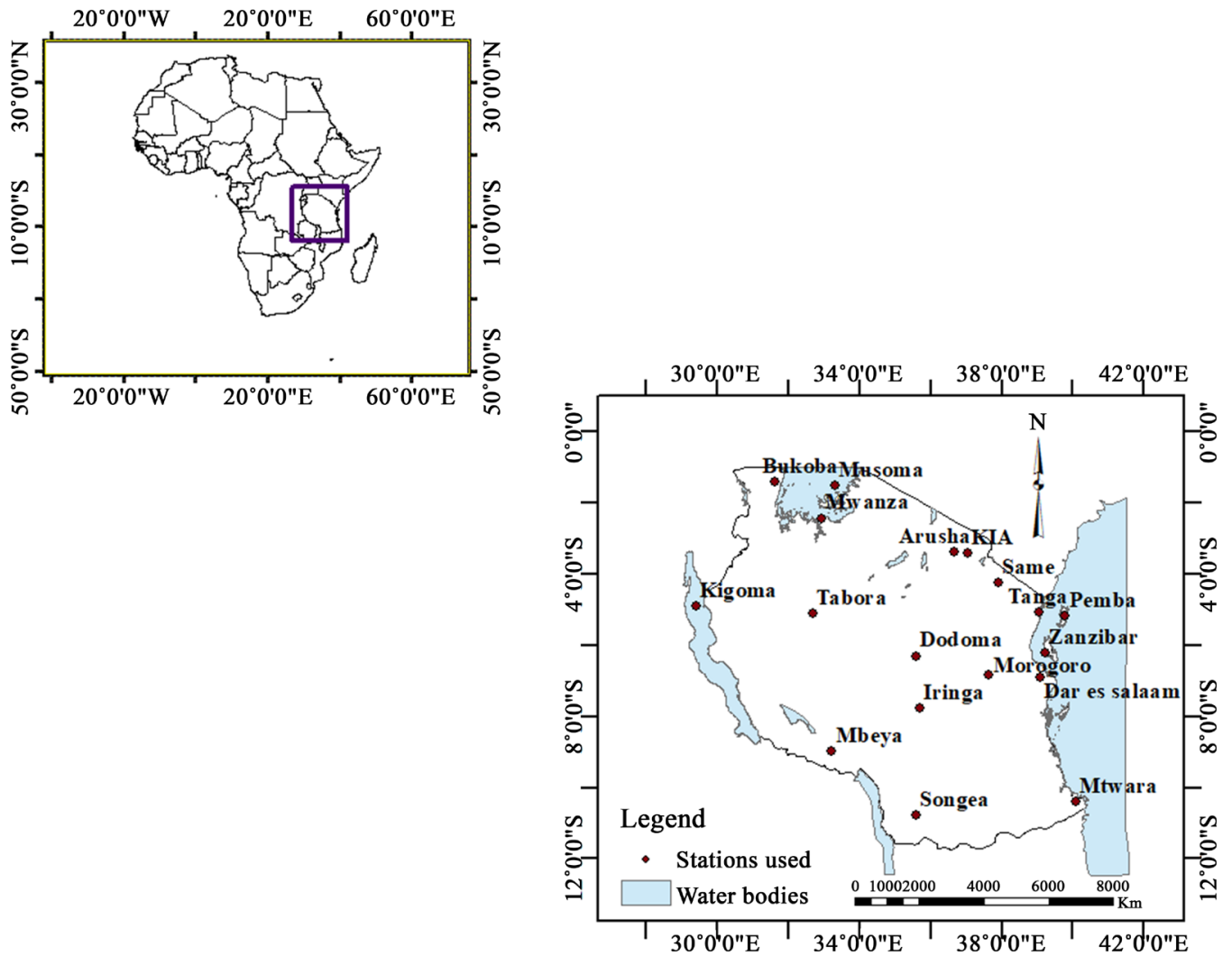

Figure 1. (a) The geographical location of Tanzania from African map; (b) 18 synoptic weather stations of which daily rainfall data were collected. 
exceeds $50 \mathrm{~mm}$ adopting similar approach as used by [16]. These HREs were then aggregated on monthly and seasonal basis for trend and temporal analysis and spatial mapping.

A number of reanalysis data sets were used to study the linkage between HREs in Tanzania and possible circulation anomalies. In this case, the monthly mean wind $(\mathrm{U}$ and $\mathrm{V})$, vertical velocity and velocity potential reanalysis data sets from the National Centers for Environmental Prediction-National Center for Atmospheric Research (NCEP-NCAR) were used [17]. These data sets span with a spatial resolution of $2.5^{\circ} \times 2.5^{\circ}$ grid after every 6 hours and are from 1949 to the present. The monthly mean SST data sets were obtained from the National Oceanic and Atmospheric Administration (NOAA) with a $2.0^{\circ} \times 2.0^{\circ}$ grid resolution for the period 1960-2017 [18]. Mean monthly ENSO Indices were computed from the tropical Pacific SST fields at an area bounded with $5^{\circ} \mathrm{S}-5^{\circ} \mathrm{N}$, $170^{\circ} \mathrm{W}-120^{\circ} \mathrm{W}$ (i.e., Nino 3.4). These indices stand for the normalized SSTA time series averaged from Nino 3.4. The IOD indices were obtained from the difference between SST observed between the western Indian Ocean $\left(50^{\circ} \mathrm{E}-\right.$ $\left.70^{\circ} \mathrm{E}, 10^{\circ} \mathrm{S}-10^{\circ} \mathrm{N}\right)$ and eastern Indian Ocean $\left(90^{\circ} \mathrm{E}-110^{\circ} \mathrm{E}, 10^{\circ} \mathrm{S}-0^{\circ}\right)$ as used earlier by a number of researchers [8] [19] [20].

\subsection{Methodology}

To determine the trends of the heavy rainfall over the study area, the sequential Mann-Kendall Trend Test [21] and [22], as used by [23] and [24] was employed. The sequential MK trend test graphically illustrates the forward, $u(F)$, and backward, $u(B)$, trends of heavy rainfall over the selected stations used in this study.

The progressive series, $u(F)$ is the standardized variable that has zero mean and unit standard deviation that its sequential performance varies around zero. When the progressive and backward series cross each other and deviates beyond the critical thresholds of upper boundary, UB $(+1.96)$ and lower boundary, LB $(-1.96)$ for $95 \%$ level of confidence, then the change points are said to be significant. According to [25] the point where the two series meet and cross each other indicates the estimated start year of the trend.

The study also used EOF to analyze the spatial and temporal variability of heavy rainfall over the study domain. The principal component (PC) corresponding to the EOF provides the sign and its amplitude and it is on the other hand marked as the HRE index in this study. The detailed description of the EOF analysis is found in [26] [27] and [28]. The method has also been widely used by a number of researchers [10] [24] [29]. The raw HREs data sets were de-trended before performing the EOF analysis. The Composite analysis method was used to determine the circulation anomalies associated with enhanced/suppressed heavy rainfall events. The key condition for the composite analysis in this study is the enhanced and suppressed events of rainfall than normal years. Thus, years for enhanced and suppressed composites were computed separately. The composites 
variables selected include meridional and zonal winds, vertical velocity, sea surface temperature and velocity potential among others. The meridional and zonal wind data set were used to determine the lower(upper) level flow which led to convergence (divergence), which then regulates the rainfall over the region. The atmospheric motion is said to be ascending (descending) when the vertical velocity anomalies values are negative (positive). The velocity potential data was used to determine centers of large-scale convergence (divergence) of positive (negative) value. The composite analysis method was also used by [14] to analyze the ENSO signals in East African rainfall, specifically for winds, vertical velocity, velocity potential relative humidity and the SST. The relationship between heavy rainfall and large-scale circulation patterns such as the ENSO and IOD was assessed using correlation analysis. More detailed information on correlation analysis can be found in [30]. The method was also employed by [29] and [24].

\section{Results and Discussion}

\subsection{Spatiotemporal Distribution of Heavy Rainfall Events}

Based on the threshold set for characterizing HREs, a total of 590 HREs have been identified for the period 1981-2015 for the 18 selected synoptic stations. The majority of these HREs are concentrated over the Lake Victoria basin with the highest number being to the western part of the Lake (Figure 2(b)) and over the northern coast.
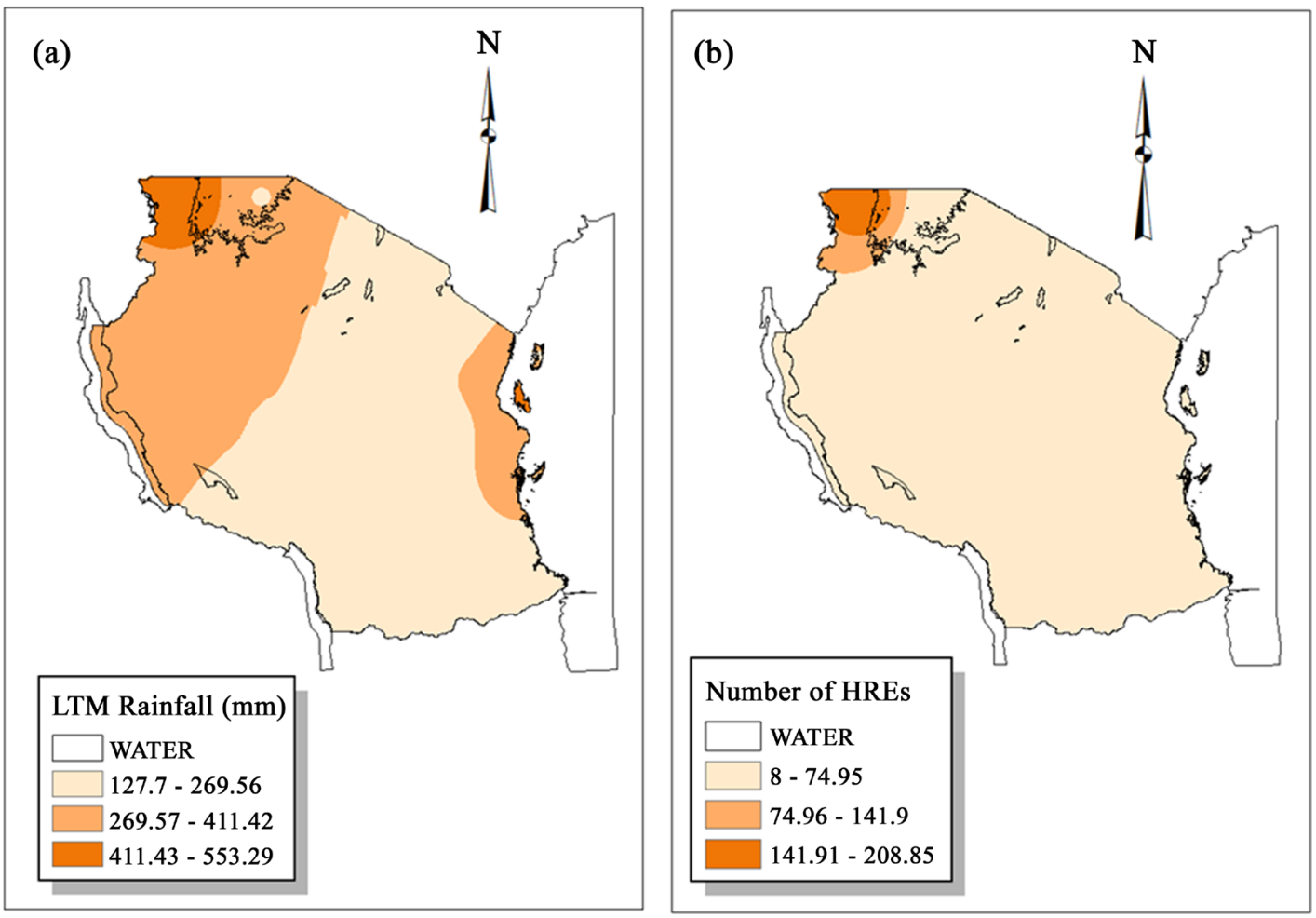

Figure 2. Spatial distribution of (a) LTM OND rainfall ( $\mathrm{mm}$ ) (b) the number of heavy rainfall events during OND rainfall season for the period 1981-2015. 
Areas around the LVB, western sector and the coastal belt of the country are associated with enhanced amount of mean monthly rainfall with high concentration being to the northern coast (Unguja and Pwani) and western and southern part of the LVB (Figure 2(a)). There is a notable agreement that, the increased number of HREs especially over the western Lake Victoria basin (Figure 2(b)) coincides with the enhanced LTM OND rains (Figure 2(a)). These facts suggest that, enhanced HREs have significant contribution to the OND rainfall over Tanzania and probably potential to associated adverse effects during the season.

The monthly variability indicates that, December records the highest number of HREs (252) followed by November (222) and October being the least affected (116) as shown in Figure 3.

\subsection{The Spatial-Temporal Variability of Heavy Rainfall Events}

The first two EOF (EOF-1 and EOF-2) describe more than 34.54\% of the total variances (Figure 4(a) \& Figure 4(b)). The spatial pattern in Figure 4(a) shows that, the first EOF (EOF-1) mode of the mean HRE anomalies explain more than $21.18 \%$ while the second EOF (EOF-2) describes more than $13.36 \%$ (Figure $4(\mathrm{~b})$ ) of the total variance. Developing the basis for the composite analysis the current study made use of the first principal component time series, PC1 in Figure 4(c). In this case, years with standardized mean heavy rainfall departure of more than positive one (>+1) were selected as enhanced HREs (1982, 1997, 2006, 2009, 2011 and 2015) while those with less than negative one $(<-1)$ are $(1985,1987,1993$, 1996, 2001, 2005, 2007, 2008 and 2010) were selected as suppressed HREs. Years with strong amplitudes of greater than +1 and -1 of standardized anomaly were later selected for the composite analysis to assess the circulation anomalies that were linked to the enhanced/suppressed heavy rainfall over the study domain. The spatial pattern of EOF-1 indicates that most of the areas have positive loading

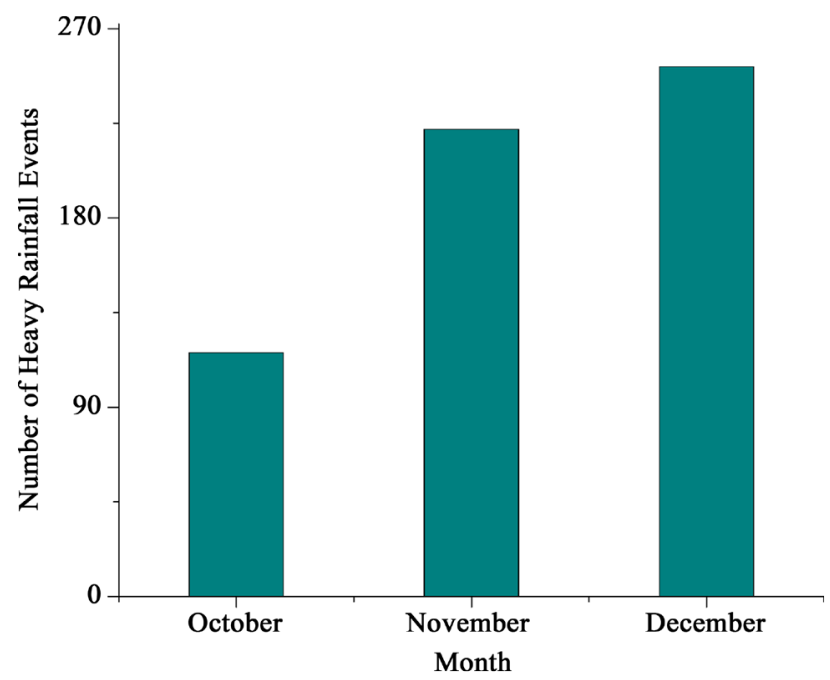

Figure 3. The monthly variability of the number of HREs during OND season of 1981 to 2015 climatology. 

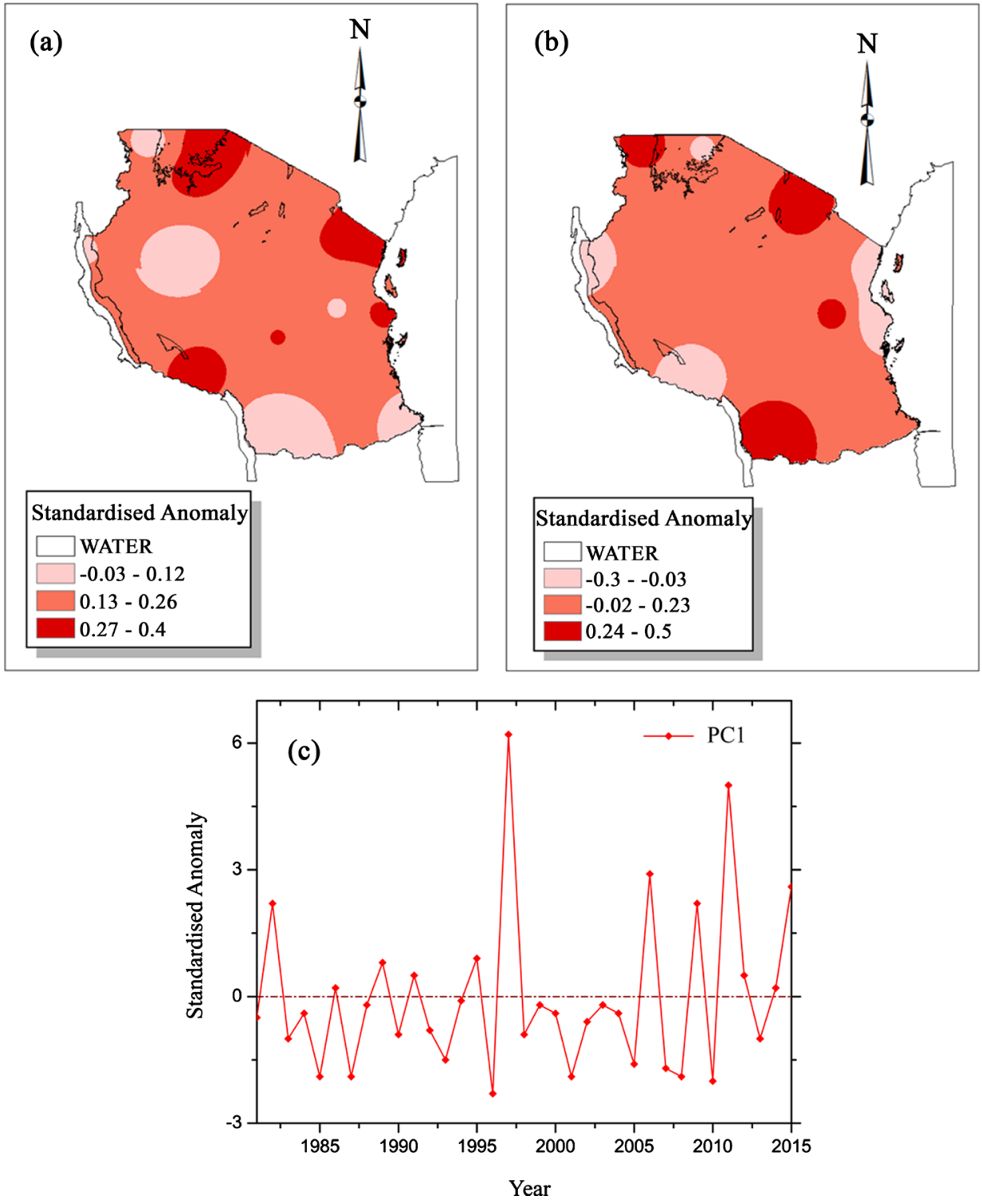

Figure 4. The spatial distribution of the (a) first EOF (EOF-1), (b) second EOF (EOF-2) modes and (c) corresponding principal component time series of the first EOF (PC1) for the mean OND HREs based on 1981 to 2015 climatology.

with an exception of few areas over western part (i.e., Tabora) and southern region (i.e., Songea).

EOF-1 in Figure 4(a) indicates that, enhanced positive loading is highly observed over the LVB (excluding the extreme western LVB) Kigoma, northern coast and some areas over the southwestern highlands (SWH) (i.e., Rukwa and Mbeya). On the other hand, EOF-2 (Figure 4(b)) has recaptured the enhanced positive loading over the western part of the LVB, the eastern part of Lake Nyasa (i.e., Songea), western (Kigoma) and over the southern coast. Both EOF modes (EOF-1 and EOF-2) in Figure 4(a) \& Figure 4(b) are in agreement with the enhanced climatological distribution of the number of HREs especially over the western LVB and western sector (Figure 2(b)) and the long term mean climato- 
logical OND rainfall over the western LVB and northern coast (Figure 2(a)).

\subsection{The Trend Analysis of Heavy Rainfall Events}

The trend of heavy rainfall during the period of study was determined using the sequential Mann-Kendal test focusing on areas around northeastern highland and Lake Victoria basin. A distinctive sequential Mann-Kendall test over the NEH (Figure 5(a)) indicates that, there was an increasing trend in HREs, and the trend was significant at $95 \%$ confidence interval from 2010 where a forward series ( $u(F))$ crossed the critical level. The abrupt change in trend increase occurred between 1985 and 2009 window. Meanwhile, the Lake Victoria basin (Figure 5(b)) depicts the decrease in trend for the HREs until 2009 where the trend learned towards increasing trend though insignificant at 95\% confidence interval. The abrupt changes in decreasing trend were observed between 1983 and 2014.

Despite the fact that, over the NEH the heavy rainfall events indicate an increasing trend, the sequential Mann-Kendall test for total rainfall (Figure 6) shows that, the stations were dominated by the decreasing trend of total rainfall during the period of study. This scenario confirms the fact that, within a season chance for HREs or rather increased HREs are likely even in seasons with low rainfall.

\subsection{Circulation Anomalies and Main Forcing Associated with Heavy Rainfall}

\subsubsection{Wind Anomalies Pattern for Enhanced/Suppressed HR}

Figure 7(a) and Figure 7(b) show the spatial distribution of wind vector anomalies for the difference between enhanced and suppressed heavy rainfall events at $850 \mathrm{hPa}$ and $200 \mathrm{hPa}$ level respectively. At low-level (Figure 7(a)) the wind flow pattern for the difference between years with enhanced and suppressed

(a) North-eastern highlands (NEH)

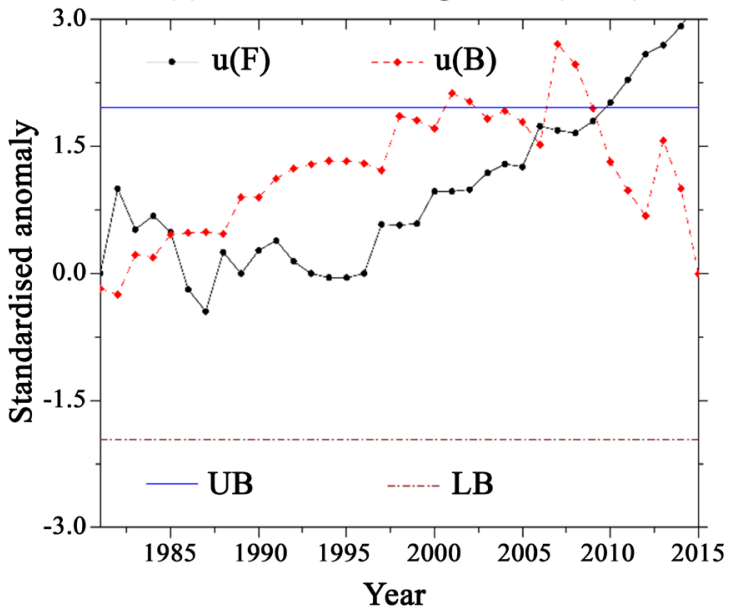

(b) Lake Victoria Basin (LVB)

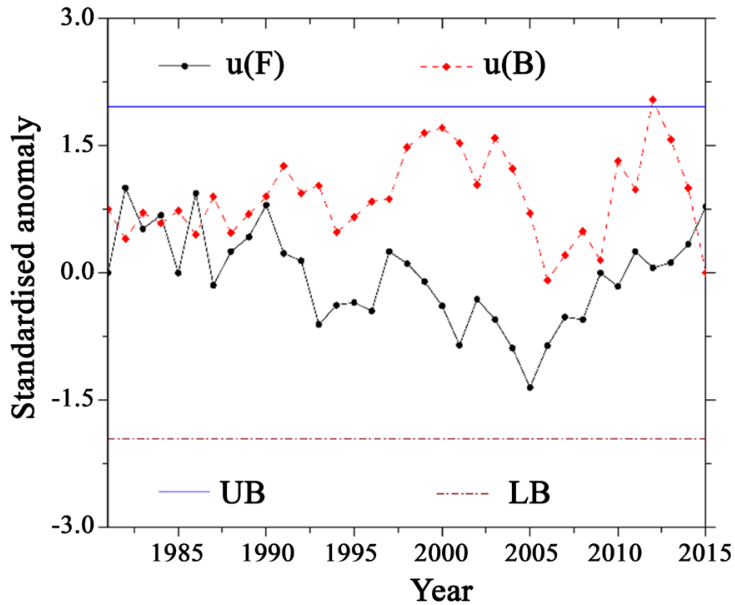

Figure 5. The time series of sequential Mann-Kendall trend tests of heavy rainfall for the two selected zones of the study area: (a) Northeastern highlands (NEH); (b) Lake Victoria Basin (LVB). The solid (blue) and dotted (red) horizontal lines show the critical values at $95 \%$ level of confidence. 


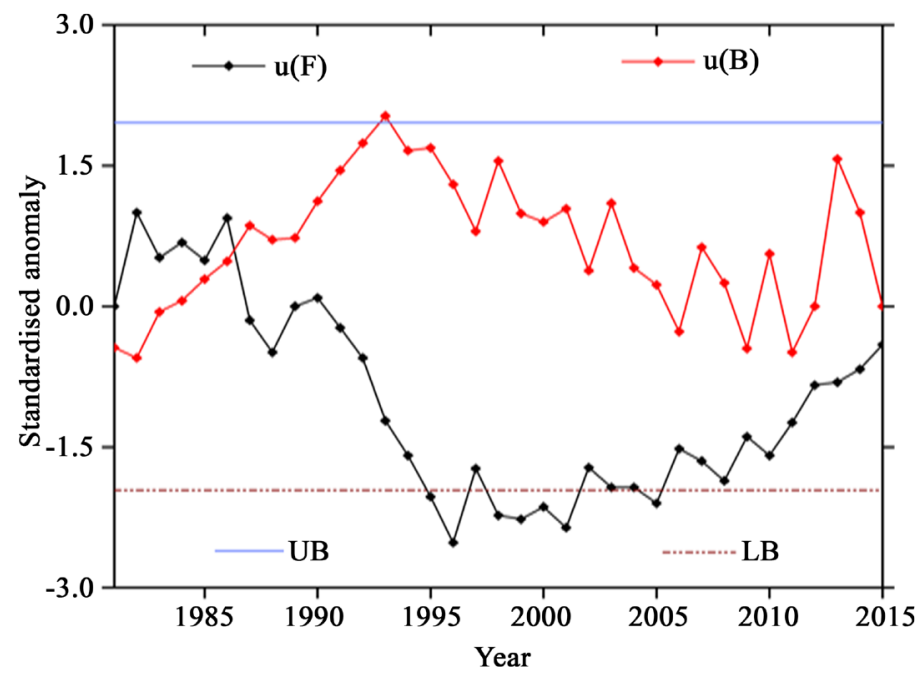

Figure 6. The Sequential Mann-Kendall trend test of total rainfall over the Northeastern highlands based on 1981 to 2015 climatology.

(a) 850 UV (Enh-Supp, HREs)

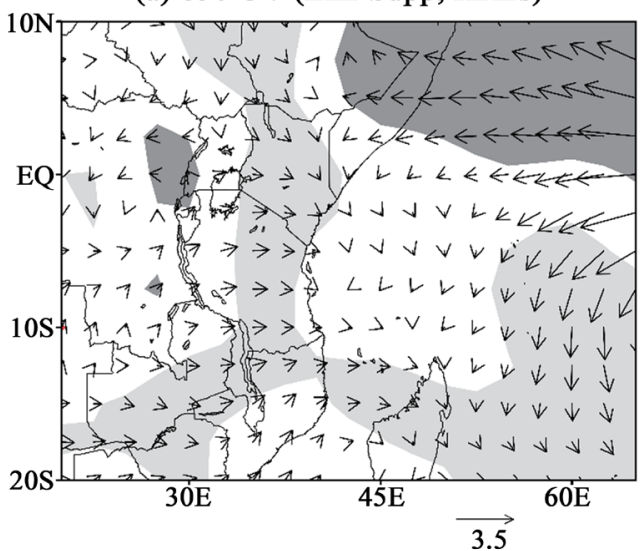

(b) 200 UV (Enh-Supp, HREs)

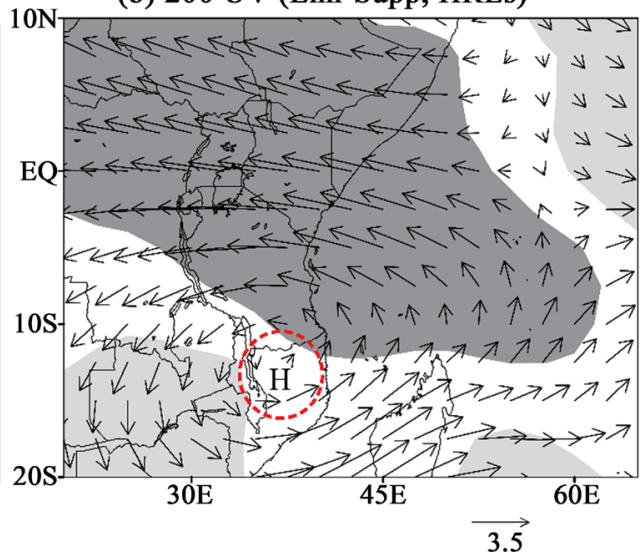

Figure 7. Composite wind vector anomalies for difference between enhanced and suppressed heavy rainfall events at (a) $850 \mathrm{hPa}$, (b) $200 \mathrm{hPa}$ based on 1981 to 2015 climatology. The shaded regions are significant areas at $95 \%$ confidence interval.

HREs, indicate the well organized moist and unstable westerly wind from Congo basin converging with the northerly wind over regions around the LVB extending towards the NEH. On the other hand, westerly winds sourced from Congo basin converge with the maritime easterly wind from the Indian Ocean along the coastal belt of the study region (Figure 7 (a)).

The upper level (Figure 7(b)) is clearly indicating the positing of the ridging over almost the entire domain of the study region, which signifies enhanced outflow motion. Since some areas around the LVB, northern coast and NEH of the country are dominated with enhanced convergence at low level and divergence in the upper level following the ridging effect, the scenario is presumed to cause the enhanced convection and associated increased number of HREs within these areas. The upper level convergences significantly lessen chances for enhanced convection at the lower level and its associated numbers of HREs. 


\subsubsection{Velocity Potential (VPT) Analysis and Wind Anomaly}

The difference between years with enhanced and suppressed HREs (Figure 8(a)) at $850 \mathrm{hPa}$ and $300 \mathrm{hPa}$ (Figure 8(b)) indicate that, during enhanced HREs, East Africa region is dominated by the ascending limb of the Walker circulation which is associated with the wind convergence (divergence) and positive (negative) velocity potential in the lower (upper) level. The ascending limb of Indian Ocean Walker circulation is clearly indicated by the vertical rising wind vectors around $60^{\circ} \mathrm{E}$ of longitude (Figure 9(a) \& Figure 9(c)). It therefore reflects the situation that, it is the enhanced convection that contributes to heavy rainfall over the study area.

During suppressed HREs it clearly indicates the positioning of the descending wind vector around $60^{\circ} \mathrm{E}$ of longitude (Figure 9(c)) depicting the descending limb of the local Indian Walker circulation which is associated with suppression of HREs within the region.

\subsubsection{The Vertical Velocity Anomaly Patterns}

Fixing the latitude and varying the longitude and atmospheric pressure it was revealed that, during years with enhanced HREs (Figure 10(a)), an ascending motion prolonging from lower level to higher levels is marked over many parts in the study domain. It also complies with the location of the ascending branch of the local Indian Ocean Walker Circulation over the East African region (Figure 9(a) and Figure 9(c)) particularly over the study area, which enhances convection of easterly winds and warm moist air mass from Congo forest hence lead to anomalously heavy rainfall events as observed within the study area. According to [11], the strong ascending and convergence of moisture observed among other factors were the crucial factors for the overwhelming floods that happened during OND 2006.

During years with suppressed HREs (Figure 10(b)), the positive vertical velocity

(a) $850 \mathrm{hPa}$ VPT (Enh-Supp, HREs)

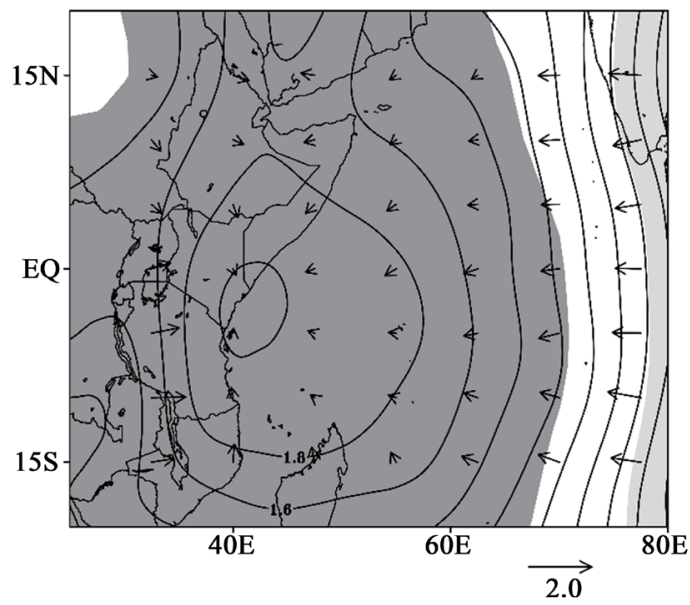

(b) $300 \mathrm{hPa}$ VPT (Enh-Supp, HREs)

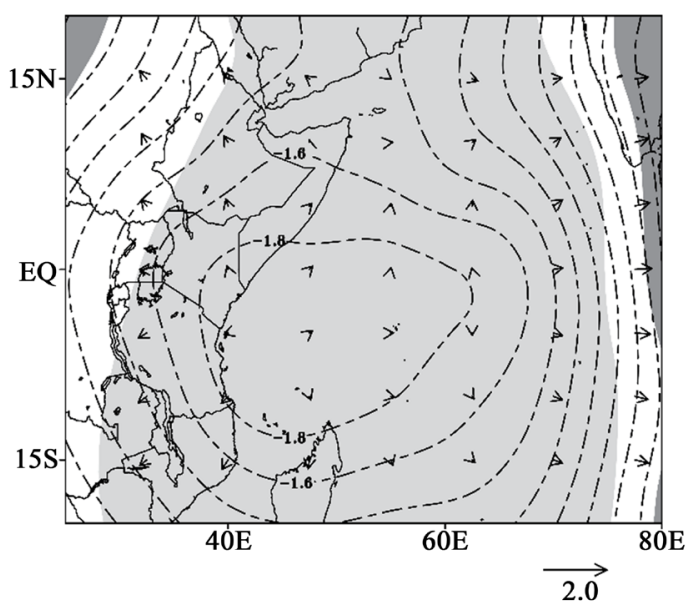

Figure 8. Composite velocity potential $\left(1 \times 10^{6} \mathrm{~m}^{2} \cdot \mathrm{s}^{-1}\right)$ and wind divergent $\left(\mathrm{s}^{-1}\right)$ anomalies for the difference between an enhanced and suppressed heavy rainfall at (a) $850 \mathrm{hPa}$ (b) $300 \mathrm{hPa}$. The dotted contour indicates the negative values of VPT. The shaded region specifies areas significance at $95 \%$ confidence level. 
(a) U-Omega*100 (Enhanced HREs)

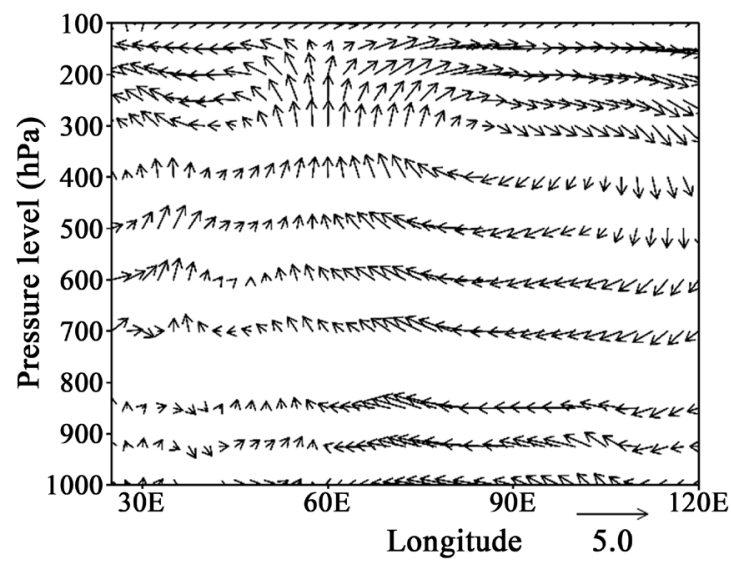

(b) U-Omega*100 (Suppressed HREs)

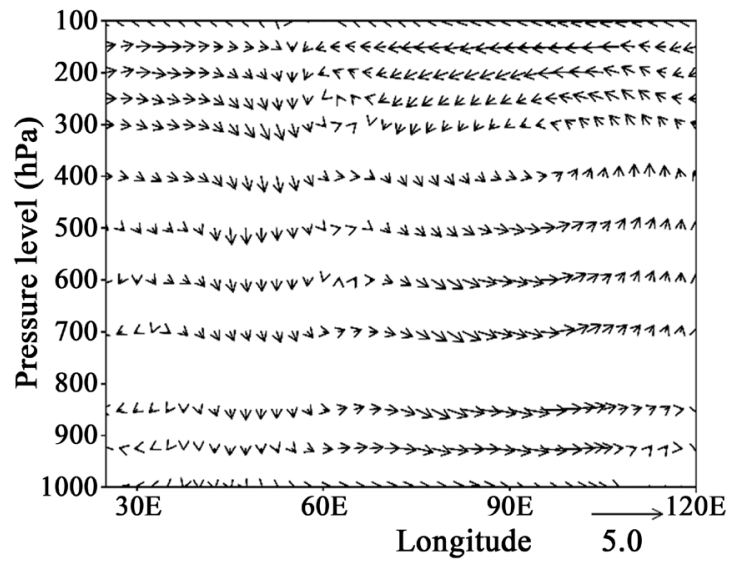

(c) U-Omega*100 (Enh-Supp, HREs)

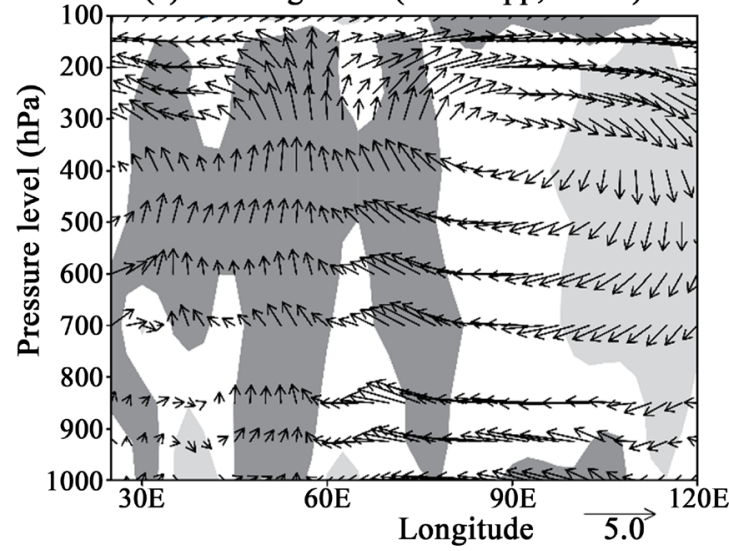

Figure 9. The composite vertical cross-section anomaly distribution of Indian Ocean Walker Circulation during (a) enhanced and (b) suppressed heavy rainfall than normal years and (c) is the difference between the distribution fields for enhanced and suppressed heavy rainfall events based on 1981 to 2015 climatology. Shaded areas in (c) indicate significant areas at $95 \%$ confidence interval.

anomalies mark the sinking motion that lead to suppressed rainfall over the study area. Analyzing years with enhanced HREs and the differences between enhanced and suppressed HREs in Figure 10(a) \& Figure 10(c) it shows that the study area is favored with significant uplift/ascending motion.

\subsubsection{Distribution of Sea Surface Temperature Anomaly (SSTA)}

Figure 11 indicates the composite patterns for the SSTA during enhanced and suppressed HREs years of the 1981 to 2015 climatology. The pattern revealed that, the rainfall experienced in this period is typically regulated by both the warm SST anomalies observed over the western equatorial Indian Ocean and the central equatorial Pacific Ocean. The enhanced heavy rainfall is observed when the equatorial western part of Indian Ocean is warmer than the eastern (western) part hence led to positive phase of IOD (Figure 11(a) \& Figure 11(c)). Meanwhile, some of the enhanced HRES are observed when SSTA (Figure 11(a) \& Figure 11(c)) over the central equatorial Pacific Ocean is warmer than normal (i.e., reflecting the warm phase of ENSO). 


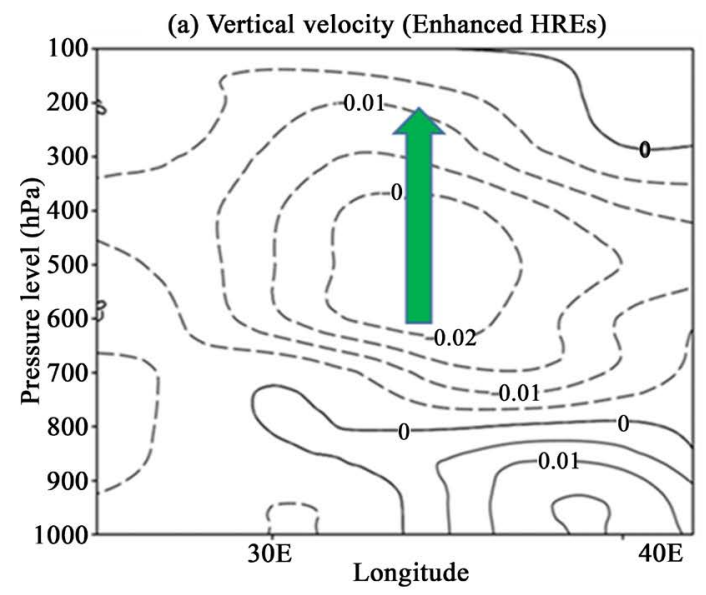

(b) Vertical velocity (Suppressed HREs)

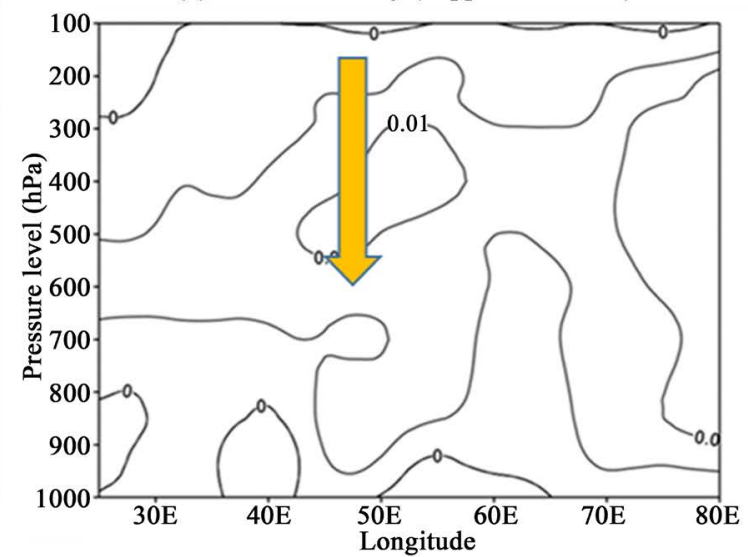

(c) Vertical velocity (Enh-Supp, HREs)

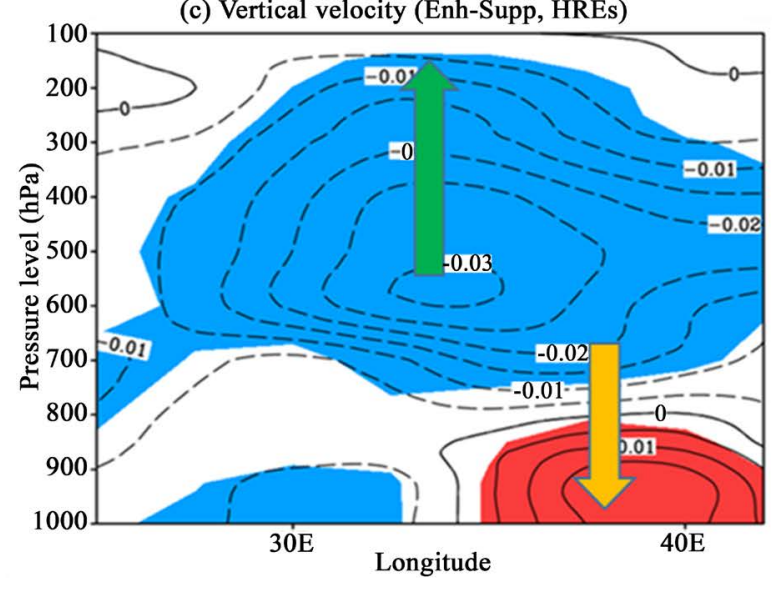

Figure 10. Spatial distribution of vertical velocity anomalies at fixed latitude for (a) an enhanced (b) suppressed heavy rainfall events than normal years and (c) the difference between vertical velocity of an enhanced and suppressed heavy rainfall events. Shaded areas in (c) indicate significant areas at $95 \%$ confidence interval; Arrows indicate the direction of motion.

The shaded region is significant at $95 \%$ confidence level. The cool SST anomalies were observed over the eastern Indian Ocean and hence mark the sign of positive IOD that could possibly be the source of enhanced amount of heavy rainfall events during the period of study. The warm SST observed over the central and eastern Pacific Ocean mark the presence of El Niño activity that also influences the occurrence of heavy rainfall over the study domain. The suppressed heavy rainfall events (Figure 11(b)) were associated with cool SST anomaly patterns over the western equatorial Indian Ocean and the central and equatorial Pacific Ocean. This condition marks negative IOD and cold phase of ENSO (i.e., La Nina condition) that led to suppressed rainfall. Therefore, during OND season the heavy rainfall events over Tanzania could be linked to SST anomalies over the Indian and Pacific Ocean.

\subsection{The Relationship between Heavy Rainfall Events and IOD and ENSO Indices}

Figure 12(a) displays the spatial pattern of correlation coefficient of mean OND 
(a) SSTA during enhanced HREs

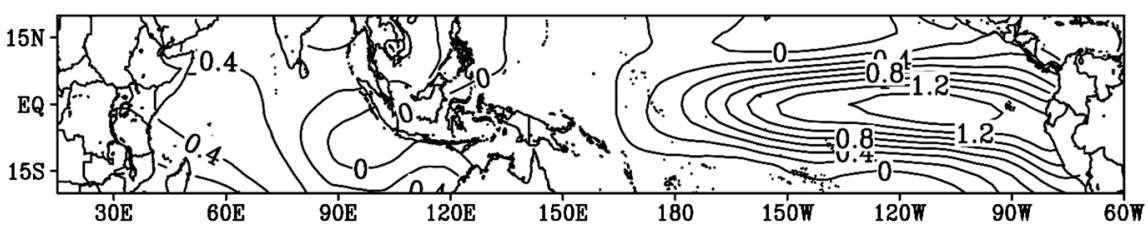

(b) SSTA during suppressed HREs

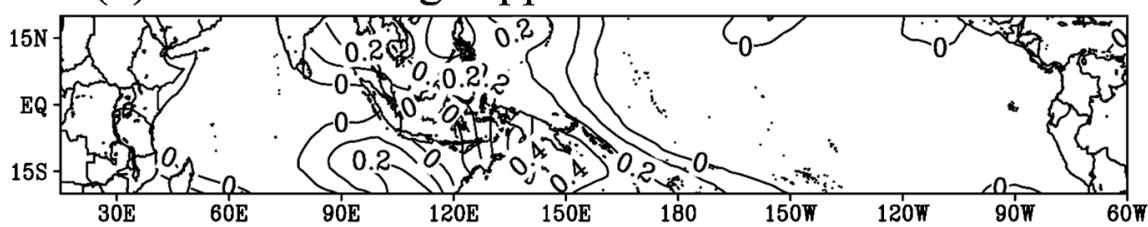

(c) SSTA during (enhanced-suppressed) HREs

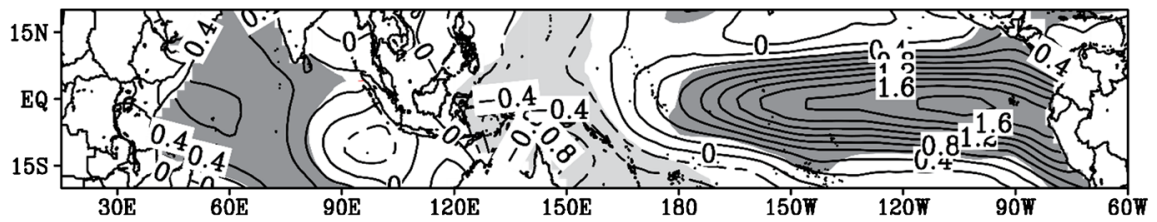

Figure 11. Spatial distribution of the composite patterns for the Sea Surface Temperature anomalies during (a) enhanced heavy (b) suppressed heavy rainfall events and (c) the differences between enhanced and suppressed HREs based on 1981 to 2015 climatology.
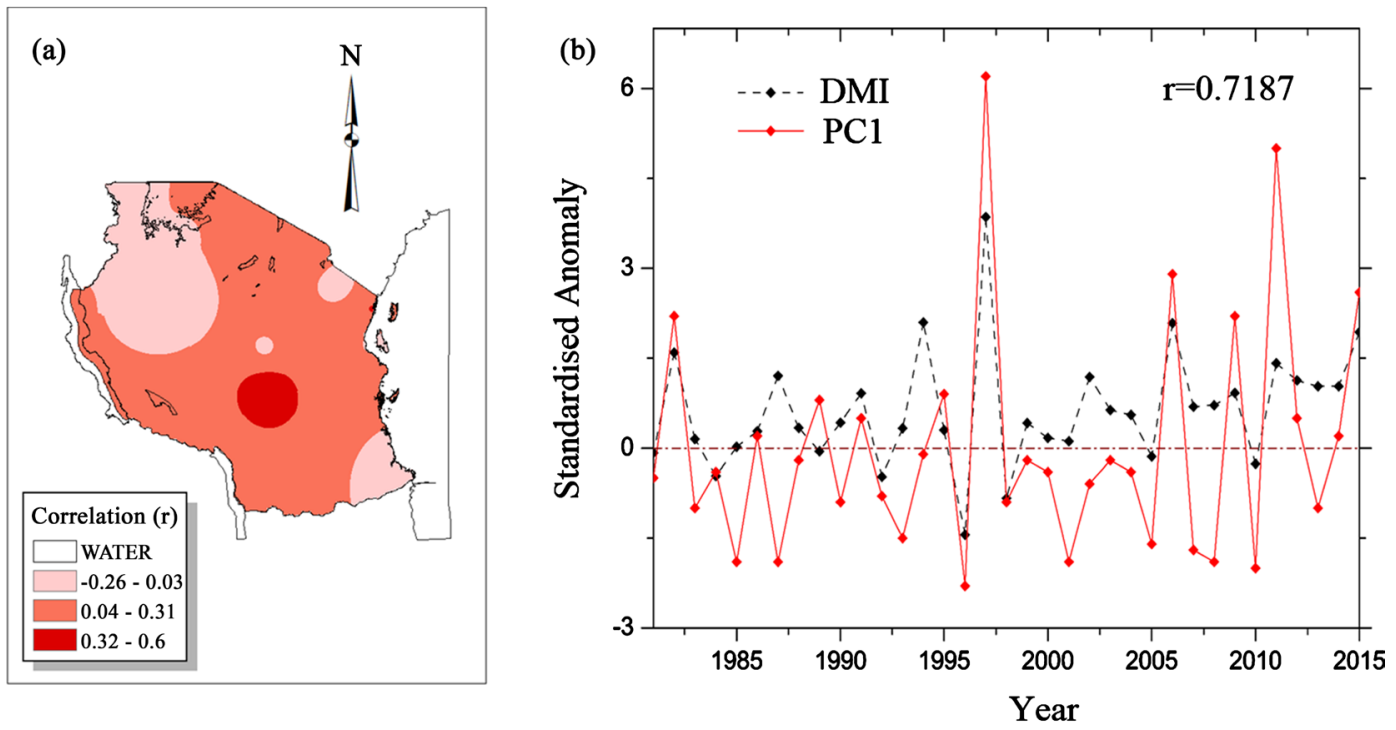

Figure 12. The (a) Spatial correlation patterns; (b) Time series of Mean OND heavy rainfall and DMI based on 1981 to 2015 climatology.

heavy rainfall and IOD indices while Figure 12(b) shows the relationship between mean heavy rainfall (PC-1) and DMI (IOD) indices over the study area. The spatial distribution in Figure 12(a) shows the strong positive correlation between HREs and IOD over the SWH, NEH and extreme northern coast (i.e., Pemba Island). The remaining areas of the study area have weak positive correlation with an exceptional of southern coast (i.e., Mtwara), western LVB, West 
(i.e., Tabora) and Same which have negative correlation. The inter-annual variability of correlation between PC-1 and IOD (Figure 12(b)) shows a strong positive correlation of about 0.7 at $95 \%$ confidence level. These results strongly comply with the earlier findings from researchers [31] and [32], who revealed a close relationship between the enhanced rainfall received along the Indian Ocean coast of east Africa and IOD (mainly positive IOD) during OND rainfall season. However, the western part of LVB shows to have more heavy rainfall events, but over those areas, the weak negative correlation is observed. This indicates that the IOD has relatively less influence on an enhanced rainfall over those areas.

The enhanced heavy rainfall events over the western part of the LVB are likely to be influenced by other physical factors, including the influence of Congo air mass [33], that significantly contribute to enhanced convection causing increase in rainfall amount over the northwestern and western sides of the Lake Victoria.

Figure 13(a) depicts the relationship between the mean OND heavy rainfall and ENSO (i.e., Nino 3.4 index). The distribution of correlation coefficient indicates a positive relationship prevailing between ENSO and mean heavy rainfall over the SWH, northern coast and over the eastern side of LVB at 95\% confidence interval. This result agrees with the finding of the researchers [34] that the enhanced rainfall over the SWH of the study area is mostly associated with the ENSO. However, no clear signal is depicted over the southern coast, and western part of the country.

The temporal correlation variability between ENSO index and PC-1 in Figure 13(b) shows a positive correlation of about 0.5 at $95 \%$ confidence interval. Therefore, it reveals that there is a relationship between the anomalous ENSO modes and the mean OND heavy rainfall events over the study area.

This result is also consistent with findings by [14] that, indicates that El Niño
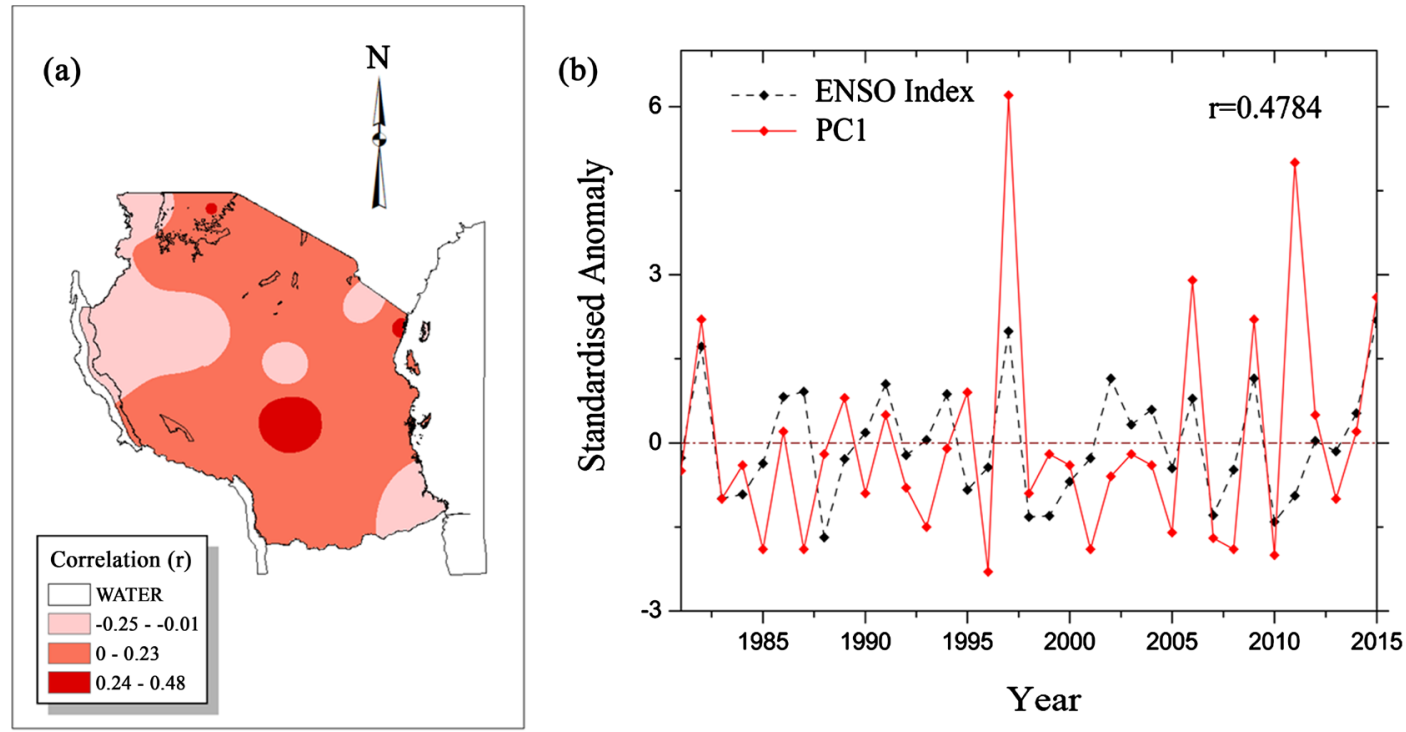

Figure 13. The (a) spatial correlation patterns; (b) Time series of Mean OND heavy rainfall and ENSO Index (Nino 3.4) based on 1981 to 2015 climatology. 
years are frequently linked to enhanced rainfall amounts during the short rainfall season over many regions. Hence, the study suggests that need for consideration of ENSO as one of the potential predictors of the heavy rainfall events.

\section{Conclusion and Recommendation}

The spatial and temporal characteristics of the HREs including their trend pattern over the period 1974 to 2010 have been analyzed, and the potential circulation patterns responsible for the variability of HREs have been extensively assessed. It has been observed that, total OND rainfall is much influenced by the numbers of heavy rainfall events in respective areas particularly during the month of November and December. HREs were more pronounced in 1997 and 2011 years during the strongest El-Nino events. The trend of HREs has been found to be more pronounced and increasing fast, particularly over the NEH. However, no clearly defined trend is depicted in other regions, including the Lake Victoria Basin where insignificant increase in HREs trend was observed towards the end of the study period. Convergence of low-level westerlies and the enhanced moisture from Congo basin associated with rising limb of Indian Ocean Walker circulation and negative vertical velocity extending from low to higher levels within those areas have been linked to occurrence of HREs, especially over the Lake Victoria Basin and over Kigoma and Tabora region. While the enhanced heavy rainfall over the northern coast including Pemba and Zanzibar Island is mostly associated with the warm SST over the western Indian Ocean and enhanced convection.

It is therefore recommended to consider circulation patterns such as vertical velocity, velocity potential, rising limb of walker circulation, IOD, ENSO and SST as potential predictors for forecasting the occurrence of HREs and other severe weather events in Tanzania.

\section{Acknowledgements}

The authors are grateful to the Tanzania Meteorological Authority (TMA), GPCC, ERSST, CEP/NCAR and NOAA/NCDC for providing the datasets used in this study. Authors would also like to thank the Chinese MOFCOM scholarship for the financial support and Nanjing University of Information Science and Technology for provision of necessary facilities and all other forms of support.

\section{Conflicts of Interest}

The authors declare no conflicts of interest regarding the publication of this paper.

\section{References}

[1] IPCC (2018) IPCC Special Report on the Impacts of Global Warming of $1.5^{\circ} \mathrm{C}$.

[2] Lal, P.N., et al. (2012) National Systems for Managing the Risks from Climate Ex- 
tremes and Disasters.

[3] Verdin, J., Funk, C., Senay, G. and Choularton, R. (2005) Climate Science and Famine Early Warning. Philosophical Transactions of the Royal Society B Biological Sciences, 360, 2155-2168. https://doi.org/10.1098/rstb.2005.1754

[4] Epstein, P.R. (1999) Climate and Health. Science, 285, 347-348. https://doi.org/10.1126/science.285.5426.347

[5] Funk, C., et al. (2005) Recent Drought Tendencies in Ethiopia and Equatorial Subtropical Eastern Africa.

[6] Reason, C.J. and Jagadheesha, D. (2005) A Model Investigation of Recent ENSO Impacts over Southern Africa. Meteorology and Atmospheric Physics, 89, 181-205. https://doi.org/10.1007/s00703-005-0128-9

[7] Hastenrath, S., Polzin, D. and Mutai, C. (2006) Diagnosing the 2005 Drought in Equatorial East Africa. Journal of Climate, 20, 4628-4637. https://doi.org/10.1175/JCLI4238.1

[8] Behera, S.K., et al. (2006) Erratum: Paramount Impact of the Indian Ocean Dipole on the East African Short Rains: A CGCM Study (Journal of Climate Vol. 18 (21) (4514-4530)). Journal of Climate, 19, 1361. https://doi.org/10.1175/JCLI3541.1

[9] Birkett, C., Murtugudde, R. and Allan, T. (1999) Indian Ocean Climate Event Brings Floods to East Africa's Lakes and the Sudd Marsh. Geophysical Research Letters, 26, 1031-1034. https://doi.org/10.1029/1999GL900165

[10] Nyenzi, B.S. (1992) Analysis of Inter-Annual Variability of Rainfall over East Africa. Journal of the African Meteorological Society, 1, 57-79.

[11] Kijazi, A.L. and Reason, C.J.C. (2009) Analysis of the 2006 Floods over Northern Tanzania. International Journal of Climatology, 29, 955-970. https://doi.org/10.1002/joc.1846

[12] Hastenrath, S., Polzin, D. and Mutai, C. (2010) Diagnosing the Droughts and Floods in Equatorial East Africa during Boreal Autumn 2005-08. Journal of Climate, 23, 813-817. https://doi.org/10.1175/2009JCLI3094.1

[13] Kabanda, T.A. and Jury, M.R. (1999) Inter-Annual Variability of Short Rains over Northern Tanzania. Climate Research, 13, 231-241. https://doi.org/10.3354/cr013231

[14] Indeje, M., Semazzi, F.H.M. and Ogallo, L.J. (2000) ENSO Signals in East African Rainfall Seasons. International Journal of Climatology, 20, 19-46. https://doi.org/10.1002/(SICI)1097-0088(200001)20:1<19::AID-JOC449>3.0.CO;2-0

[15] Ummenhofer, C.C., Sen Gupta, A., England, M.H. and Reason, C.J.C. (2009) Contributions of Indian Ocean Sea Surface Temperatures to Enhanced East African Rainfall. Journal of Climate, 22, 993-1013. https://doi.org/10.1175/2008JCLI2493.1

[16] Brigadier, L., Ogwang, B.A., Ongoma, V., Ngonga, C. and Nyasa, L. (2016) Diagnosis of the 2010 DJF Flood over Zambia. Natural Hazards, 81, 189-201. https://doi.org/10.1007/s11069-015-2069-Z

[17] Kalnay, E., et al. (1996) The NCEP/NCAR 40-Year Reanalysis Project. Bulletin of the American Meteorological Society, 77, 437-471. https://doi.org/10.1175/1520-0477(1996)077<0437:TNYRP>2.0.CO;2

[18] Smith, T.M., Reynolds, R.W., Peterson, T.C. and Lawrimore, J. (2008) Improvements to NOAA's Historical Merged Land-Ocean Surface Temperature Analysis (1880-2006). Journal of Climate, 21, 2283-2296. https://doi.org/10.1175/2007JCLI2100.1

[19] Saji, N.H., Goswani, B.N., Vinayachandran, P.N. and Yamagata, T. (1999) A Dipole 
Mode in the Tropical Indian Ocean. Nature, 401, 360-363. https://doi.org/10.1038/43854

[20] Muhati, F., Ininda, J. and Opijah, F.J. (2007) Relationship between ENSO Parameters and the Trends and Periodic Flactuations in East African Rainfall. Journal of Kenya Meteorological Society, 1, 20-43.

[21] Mann, H.B. (1945) Nonparametric Tests against Trend. Econometrica, 13, 245-259. https://doi.org/10.2307/1907187

[22] Kendall, M.G. (1975) Rank Correlation Methods. Griffin, London.

[23] Nasri, M. and Modarres, R. (2009) Dry Spell Trend Analysis of Isfahan Province, Iran. International Journal of Climatology, 29, 1430-1438. https://doi.org/10.1002/joc.1805

[24] Limbu, P.T.S. and Guirong, T. (2019) Relationship between the October-December Rainfall in Tanzania and the Walker Circulation Cell over Indian Ocean. Meteorologische Zeitschrift, 28, 453-469. https://doi.org/10.1127/metz/2019/0939

[25] Mosmann, J., Castro, V., Fraile, A., Dessens, R. and Sánchez, J. (2004) Detection of Statistically Significant Trends in the Summer Precipitation of Mainland Spain. Atmospheric Research, 70, 43-53. https://doi.org/10.1016/j.atmosres.2003.11.002

[26] Lorenz, E.N. (1956) Empirical Orthogonal Functions and Statistical Weather Prediction. Statistical Forecasting Project Rep. 1.

[27] Hotelling, H. (1933) Analysis of a Complex of Statistical Variables into Principal Components. Journal of Educational Psychology, 24, 498-520. https://doi.org/10.1037/h0070888

[28] Bjornsson, H. and Venegas, S.A. (1997) A Manual for EOF and SVD Analyses of Climate Data.

[29] Mafuru, K.B. and Guirong, T. (2018) Assessing Prone Areas to Heavy Rainfall and the Impaction of the Upper Warm Temperature Anomaly during March-May Rainfall Season in Tanzania. Advances in Meteorology, 2018, Article ID: 8353296. https://doi.org/10.1155/2018/8353296

[30] Yount, R. (2006) Correlation Coefficients. Research Design and Statistical Analysis in Christian Ministry. 4th Edition. Department of Foundations of Education, School of Religious Education, Southwestern Theological Seminary, Fort Worth, TX, 71-72.

[31] Black, E., Slingo, J. and Sperber, K.R. (2003) An Observational Study of the Relationship between Excessively Strong Short Rains in Coastal East Africa and Indian Ocean SST. Monthly Weather Review, 131, 74-94. https://doi.org/10.1175/1520-0493(2003)131<0074:AOSOTR>2.0.CO;2

[32] Clark, C.O., Webster, P.J. and Cole, J.E. (2003) Interdecadal Variability of the Relationship between the Indian Ocean Zonal Mode and East African Coastal Rainfall Anomalies. Journal of Climate, 16, 548-554. https://doi.org/10.1175/1520-0442(2003)016<0548:IVOTRB >2.0.CO;2

[33] Nicholson, S.E. (1996) A Review of Climate Dynamics and Climate Variability in Eastern Africa. In: Johnson, T. and Odada, E., Eds., The Limnology, Climatology and Paleoclimatology of the East African Lakes, CRC Press, Boca Raton, 25-56. https://doi.org/10.1201/9780203748978-2

[34] Mbululo, Y. and Nyihirani, F. (2012) Climate Characteristics over Southern Highlands Tanzania. Atmospheric and Climate Sciences, 2, 454-463.

https://doi.org/10.4236/acs.2012.24039 